\title{
Objectification of indications for surgical restoration of the plantar plate in the treatment of multiplanar static foot deformities accompanied by hammertoe deformity of the lesser toes using ultrasound
}

\author{
V.N. Cherevtsov ${ }^{1}$, A.N. Blazhenko ${ }^{2}$, S.B. Bogdanov ${ }^{2}$, A.V. Mazalov ${ }^{3}$, M.S. Ketov ${ }^{4}$ \\ ${ }^{1}$ City Clinical Hospital № 3, Krasnodar, Russian Federation \\ ${ }^{2}$ Kuban State Medical University, Krasnodar, Russian Federation \\ ${ }^{3}$ Moscow Research Centre Name after A.S. Loginov, Moscow, Russian Federation \\ ${ }^{4}$ City Clinical Hospital № 1 Novokuznetsk, Russian Federation
}

\begin{abstract}
Introduction Progressive multiplanar static deformity of the forefoot can result in hallux valgus, metatarsus primus varus, transverse flat foot and associated overload of the metatarsophalangeal joints (MTPJ) with plantar plate degeneration and rupture of MPT joints of the lesser toes leading to hammertoe deformity. Diagnostic ultrasound in the identification of plantar plate tears is easy to use at any medical center of the Russian Federation with orthopaedic services and provide a relatively inexpensive option compared with other advanced imaging modalities. The goal was to present ultrasound technology for accurate evaluation of the severity of plantar plate injury which may provide guidance for surgical treatment of hammertoe deformity of the lesser toes in patients with multiplanar static forefoot deformity. Material and methods The study recruited 88 participants with multiplanar static deformity of the forefoot, who underwent ultrasound evaluation according to the original method (RF Patent No. 2699383 "Method for determining the type of degenerative rupture of the plantar plate of the metatarsophalangeal joint due to overload metatarsalgia") to objectify the results of a physical examination with the Hamilton-Thompson test performed for identifying the degree of instability of the MTPJ, and nonparametric analysis was produced with Pearson's Chi-square test. Results Evaluation of the severity of plantar plate injury in the study group of patients $(n=88)$ with the Hamilton-Thompson test and ultrasound imaging showed diagnostic error in $22.8 \%$ of cases with the use of clinical methods that allowed reasonable reduction of surgical intervention in $2.3 \%$ and substantial correction of the treatment approaches in $20.5 \%$ preventing a complete plantar plate tear. Discussion The ultrasound scanning introduced in the algorithm for diagnosing the degree of plantar plate rupture facilitated an objective approach to the choice of the most appropriate treatment strategy for complicated multiplanar forefoot deformities accompanied by a non-rigid hammertoe deformity of lesser toes. Conclusion Preoperative ultrasound imaging of the plantar surface of the foot for detecting the severity of plantar plate injury should be included in the diagnostic algorithm for patients with complicated multiplanar forefoot deformities accompanied by a non-rigid hammertoe deformity of lesser toes.
\end{abstract}

Keywords: hallux valgus, non-rigid hammertoe deformity of lesser toes, plantar plate, Hamilton-Thompson test, ultrasonography

Progressive multiplanar static deformity of the forefoot can result in hallux valgus, metatarsus primus varus, transverse flat foot and associated overload of the metatarsophalangeal joints (MTPJ) [1-6] with plantar plate degeneration and rupture of MPTJs of the lesser (the second, third or fourth) toes leading to hammertoe deformity with subluxed and/or dislocated toe, dislocation of the flexor tendons, maltraction of the vermiform muscles, hyperextended toe) [7]. Distal scarf [1, 8-11], chevron [9, 12-14], MICA [15-17] osteotomies of the first metatarsal bone have been commonly used since the second half of the XXth and the beginning of the XXIst century to correct hallux valgus and metatarsus primus varus with the osteotomy produced at the apex of the deformity reducing the first-second metatarsal angle with less complication and recurrence rates. The extent of the plantar plate injury and other MPTJ stabilizers can often be disregarded with the approaches developed to address non-rigid hammertoe deformity of lesser toes which leads to the use of unreasoned surgical interventions including the plantar plate plasty $[3,7,18-20]$. The recurrence of hammertoe deformity of the lesser toes, the floating toe syndrome, rigid hammertoe deformity are reported to occur in $20-54 \%$ of cases $[6,12$, 21-24]. Failures in the surgical treatment of hammertoe deformity can be caused by subjective/inaccurate methods of diagnosing a plantar plate injury [2]. The degree of instability of the MTPJ was described and graded by Thompson and Hamilton. The HamiltonThompson metatarsophalangeal "drawer" test can identify stability of the MPTJ joint in $93 \%$ and assess pain in $94 \%$ of cases and fails to accurately diagnose a plantar plate tear $[2,12,21]$. Magnetic resonance imaging (MRI) $[25,26]$ of the forefoot as a wellrecognized and accepted diagnostic tool may also be useful to identify a plantar plate tear but the imaging technique is expensive and can be unavailable in most medical institutions in Russia, and interpreting an MRI scan can be technically demanding. The ultrasonic imaging as relatively inexpensive and widely available method may also be useful to identify plantar plate tear. Ultrasound is an efficient choice in the identification of plantar plate tears. The use of diagnostic ultrasound in the detection of plantar plate tears is important for surgical criteria as the reference test.

Cherevtsov V.N., Blazhenko A.N., Bogdanov S.B., Mazalov A.V., Ketov M.S. Objectification of indications for surgical restoration of the plantar plate in the treatment of multiplanar static foot deformities accompanied by hammertoe deformity of the lesser toes using ultrasound. Genij Ortopedii, 2021, vol. 27, no 2, pp. 214-219. DOI 10.18019/1028-4427-2021-27-2-214-219 
The goal was to present ultrasound technology for accurate evaluation of the severity of plantar plate tears which may provide guidance for surgical treatment of hammertoe deformity of the lesser toes in patients with multiplanar static forefoot deformity.

\section{MATERIAL AND METHODS}

A study recruited 88 patients who received treatment at the orthopedic and trauma department of the City Clinical Hospital № 3, Krasnodar, and at the orthopedic department of the multidisciplinary medical center "In Good Hands", Krasnodar, between 2014 and 2019. The inclusion criteria were radiologically verified static multiplanar deformity of the forefoot (hallux valgus, metatarsus primus varus, transverse flat foot) and clinical signs of MTPJ instability in lesser toes including instability of the MTPJ without evident hammertoe deformity of the second or the second and the third toes $(n=4)$, subluxed and/or dislocated toe, dislocated flexor tendons, hyperextended toe $(\mathrm{n}=78)$, rigid hammertoe/claw deformity $(n=6)$. To objectify the extent of plantar plate tear, we compared the results of a clinical examination using the HamiltonThompson test to measure the degree of instability with ultrasound findings of 88 patients presented with static multiplanar foot deformity using the grading system: G0, stable MTPJ; G1, unstable MTPJ; G2, subluxed MTPJ; G3, completely dislocated MTPJ; $\mathrm{G} 4$, rigid hammertoe deformity of lesser toes $[1,22]$.

The Hamilton-Thompson MTP drawer test was performed with the head and neck of metatasral bone fixed by one hand. The examiner attempted to dislocate the proximal phalanx dorsally with the other hand assessing the severity of the pain and the degree of dorsal displacement in the MTPJ joint (Figure 1).
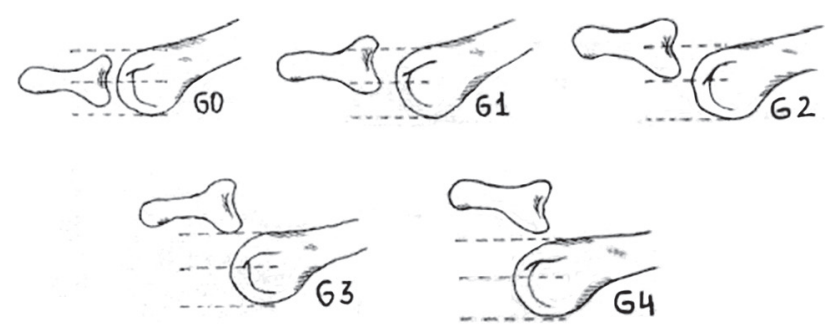

Fig. 1 Degree of displacement of the major phalanx with different plantar plate tears evaluated with the HamiltonThompson drawer test

Sonographic scanning was performed according to the original method [27]. With medium viscosity mediagel applied, the transducer was placed over the plantar surface of the metatarsal heads to explore the structural integrity of the plantar plate, orientation of the fibers, edema of the surrounding tissues, changes in the membranes of the flexor digitorum longus muscle, the presence or absence of phalangeal dislocation and dislocation in the MTPJ. The instability was graded as
- the Hamilton-Thompson G0 with sonographic absence of fibrous thinning of the plantar plate, presence of moderate edema and infiltration of the plantar plate, absent edema and infiltration in the membranes of the flexor digitorum longus muscle and dislocation of the major phalanx;

- the Hamilton-Thompson G1 with fibrous thinning of the plantar plate, thin fibers at the metatarsal head, impaired parallel fibrous orientation, moderate edema and infiltration of the membranes of the flexor digitorum longus muscle, absent dislocation of the major phalanx, absent subluxation of the MTPJ;

- the Hamilton-Thompson G2 with impaired fibers of the plantar plate at the metatarsal head of less than $50 \%$, evident edema and infiltration of the membranes of the flexor digitorum longus muscle, $30 \%$ dislocation of the major phalanx and clinical subluxation of MTPJ;

- the Hamilton-Thompson G3 with more than $50 \%$ impaired fibers of the plantar plate at the metatarsal, edema and infiltration of the plantar plate and the membranes of the flexor digitorum longus muscle, overextended MTPJ with dislocation of the major phalanx by $50 \%$ and over with the possibility of complete reduction of the MTPJ;

- the Hamilton-Thompson G4 with completely $(100 \%)$ impaired fibers of the plantar plate at the metatarsal, edema and infiltration of the plantar plate and the membranes of the flexor digitorum longus muscle, dislocation of the MTPJ and dislocation at the base of the toe and complete irreducable dislocation of the MTPJ;

The study was performed in accordance with ethical principles for medical research involving human subjects stated in the Declaration of Helsinki developed by the World Medical Association as revised in 2013 and Order of the Ministry of Health of the RF dtd 19th June 2003 No. 266 on Clinical Practice Guidelines in the Russian Federation. Statistical analysis of clinical results was performed using descriptive statistics with the distribution of values, nonparametric statistics to test the null hypothesis, Pearson's chi-squared test with arbitrary tables to identify differences in variables in unrelated samples [28]. For calculations, a significance level of $<0.05$ was adopted. Statistical analysis was performed with computer software: Microsoft Office Excell 2010 and SPSS, version 16.0 for Windows. 


\section{RESULTS}

Comparative analysis of patients with G0 and G4 instability showed no significant statistical difference in physical examination and ultrasound findings (Table 1) with the results of physical examination being consistent with ultrasound findings in $100 \%$ of G0 patients who had no injury to the plantar plate (Fig. 2).

Patients with instability graded G1 $(n=17)$ (Fig. 3, 4) with clinical testing showed plantar plate tear graded G2 ( $\mathrm{n}=6 ; 35.3 \%)$ (Fig. 5 and 6$)$ with ultrasound which allowed timely amendments in surgical intervention with suturing the plantar plate (Table 1).

Sonographic scan of patients with plantar plate tear graded G2 $(n=27)$ with clinical test (Fig. 7) showed plantar plate tear sonographically graded G3 $(n=7)$ (Fig. 8) and indicated an emergency surgical intervention to avoid transition to grade G4. Plantar plate tear graded G2 $(n=2)$ with clinical test was sonographically assessed as G1 and allowed reduction in the volume of surgical procedure. Overall, errors occurred in $22.8 \%$ of plantar plate tears graded clinically (Table 1 ).

Table 1

Comparative analysis of plantar plate injury graded with the Hamilton-Thompson test and ultrasound findings

\begin{tabular}{|c|c|c|c|c|c|}
\hline \multirow{3}{*}{\begin{tabular}{|c} 
Types of injury to \\
plantar plate as graded \\
with the Hamilton- \\
Thompson test \\
\end{tabular}} & \multicolumn{5}{|c|}{ Distribution of patients with plantar plate tears graded with clinical test and ultrasound } \\
\hline & \multirow{2}{*}{$\begin{array}{l}\text { Clinical test of } \\
\text { plantar plate tear } \\
\text { abs. }\end{array}$} & \multicolumn{2}{|c|}{$\begin{array}{l}\text { False results of clinical } \\
\text { testing the plantar plate tear }\end{array}$} & \multirow{2}{*}{$\begin{array}{l}\text { Extent of plantar plate tear } \\
\text { evaluated with ultrasound } \\
\text { abs. }\end{array}$} & \multirow[t]{2}{*}{ significance } \\
\hline & & abs. & $\%$ & & \\
\hline G0 & 4 & 0 & 0 & 4 & - \\
\hline G1 & 17 & G2-6 & 35.3 & 13 & $\chi^{2}=5.3, \mathrm{p}=0.021$ \\
\hline \multirow{2}{*}{ G2 } & \multirow{2}{*}{27} & G1-2 & \multirow{2}{*}{33.3} & \multirow{2}{*}{29} & \multirow{2}{*}{$\chi^{2}=10.3, p=0.002$} \\
\hline & & G3-7 & & & \\
\hline G3 & 35 & G2-5 & 14.2 & 37 & $\chi^{2}=5.6, p=0.018$ \\
\hline G4 & 5 & 0 & 0 & 5 & - \\
\hline Total & 88 & 20 & 22.7 & 88 & - \\
\hline
\end{tabular}

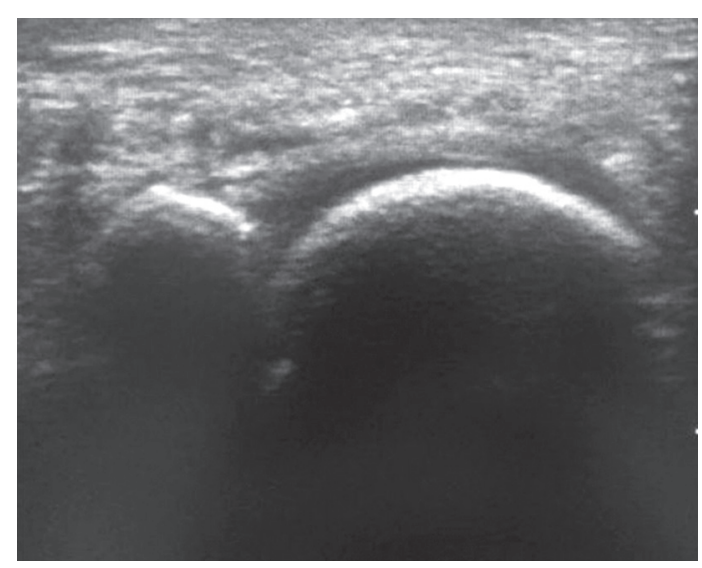

Fig. 2 Sonographic scan showing absent plantar plate tear graded G0

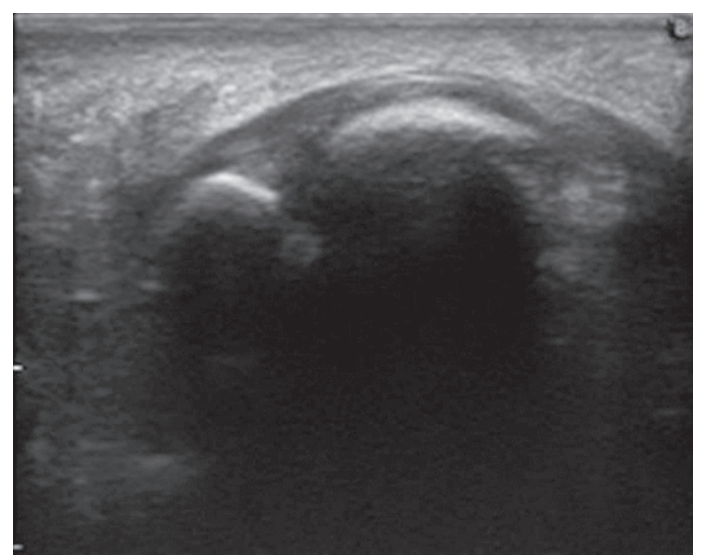

Fig. 4 Sonographic scan showing plantar plate tear graded G1 with the Hamilton-Thompson test

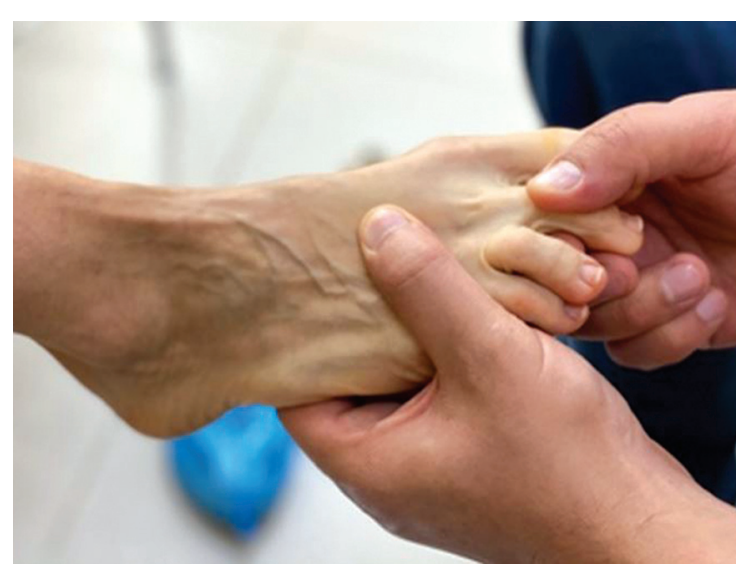

Fig. 3 Displacement of the major phalanx with plantar plate tear graded G1 with the Hamilton-Thompson test

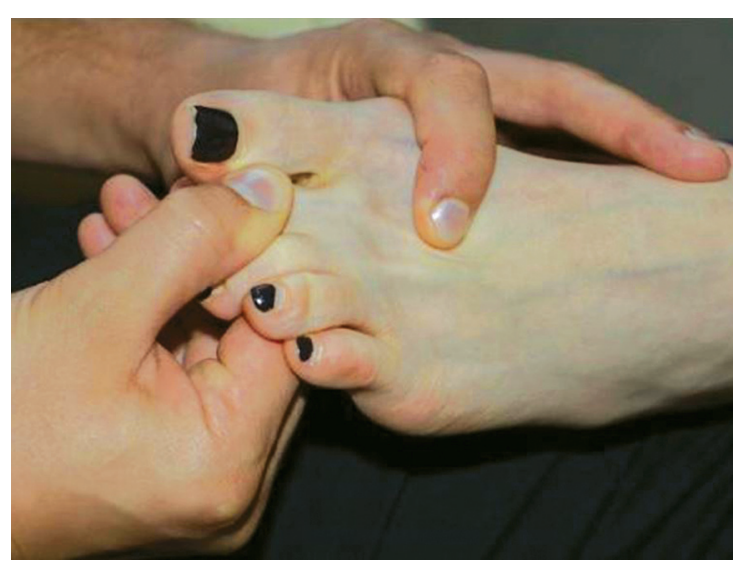

Fig. 5 Displacement of the major phalanx with plantar plate tear graded $\mathrm{G} 2$ with the Hamilton-Thompson test 


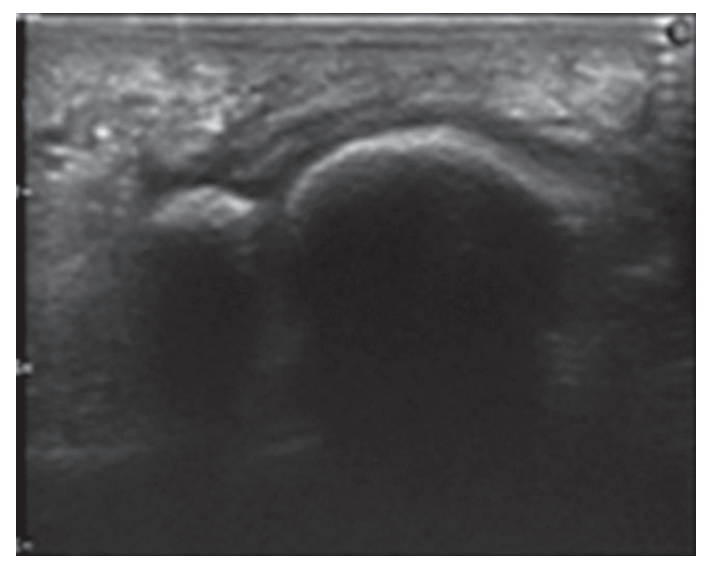

Fig. 6 Sonographic scan showing plantar plate tear graded G2 with the Hamilton-Thompson test

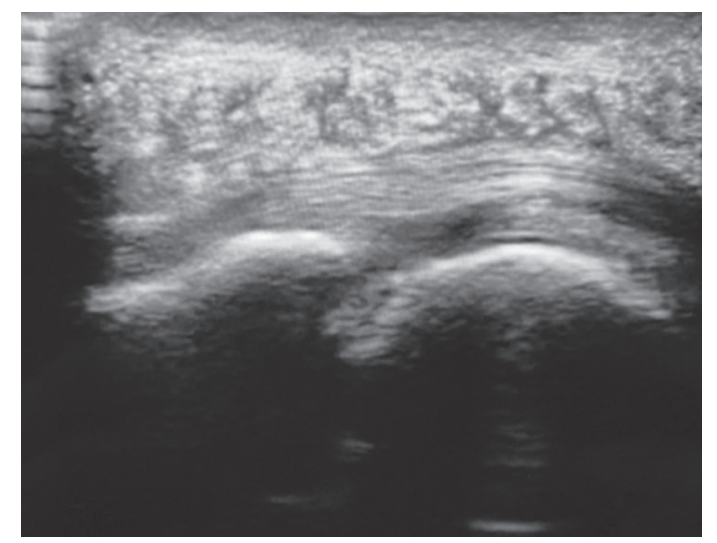

Fig. 8 Sonographic scan showing plantar plate tear graded G2 with the Hamilton-Thompson test

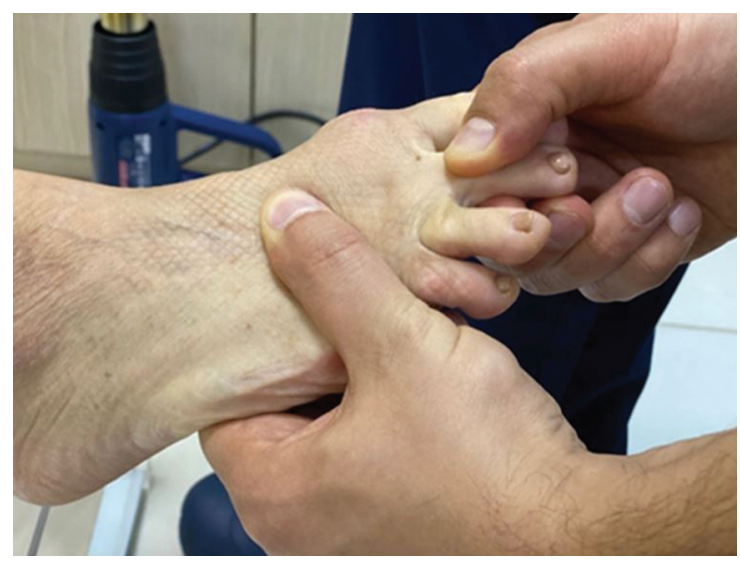

Fig. 7 Displacement of the major phalanx with plantar plate tear graded G3 with the Hamilton-Thompson test

Among 35 plantar plate tears clinically graded G3 five $(14.3 \%)$ were sonographically assessed as G2 and indicated an emergency surgical intervention to avoid progression and transition to complete plantar plate tear.

Diagnostic inaccuracies of clinical testing of plantar plate tears occurred in $22.8 \%$ of cases with $2.3 \%$ of patients treated with reasonably reduced volume of surgical intervention, and treatment strategy was significantly adjusted in $20.5 \%$ to avoid a complete plantar plate tear.

\section{DISCUSSION}

Acquired forefoot deformity is a common problem with severe restrictions in quality of life and impairment of daily activities. Foot deformities can lead to pain, and change in the walking style, difficulties with footwear and aesthetic concerns. Deformities of lesser toes are more common in the forefoot being a component of a complicated multiplanar deformity associated with hallux valgus $[6,12,18,20,29]$. These deformities (hammertoe deformity of the smaller toes) can also occur as an isolated pathology $[6,20,30,31]$. Evaluation of instability with plantar plate tear using the HamiltonThompson test can be subjective and based on the personal findings of the examiner with no objectivity. There are no accurate criteria for evaluation of the plantar plate tear and differentiating between grades G2 and G3 can be difficult. The use of subjective diagnosis and the identity of clinical manifestations can be misleading in grading the G1 and G2 plantar plate tears, and they appear to be combined in one cluster of the anatomical classification [1, 32, 33]. Ultrasound allows assessment of the plantar plate tear under tension with the load and during movements in the MTPJ. Specific foot structures, peripheral edema or excessive soft tissue in obese patients can interefere with the accuracy of the Hamilton-Thompson test.

Preoperative ultrasound examination of the plantar foot is crucial for the diagnosis of complicated static multiplanar deformity of the forefoot accompanied by non-rigid hammertoe deformity of the second and/ or second, third toes to identify the extent of plantar plate tear and surgical strategy based on the following:

G0 - stable MTPJ with no anatomical injury to the plantar plate and hammertoe deformity - no surgical treatment indicated;

G1 - unstable MTPJ with no anatomical injury to the plantar plate, with hammertoe deformity to be corrected due to degenerative changes in the stabilizers of the MTPJ - the Weil procedure is indicated with no need for plasty of the plantar plate;

G2 - subluxation of the MTPJ with anatomical injury to the plantar plate and non-rigid hammertoe deformity of lesser toes to be addressed with Weil surgery and plasty of the plantar plate;

G3 - severe injury to the MTPJ with anatomical injury to the plantar plate, complete dislocation in 
the joint, non-rigid hammertoe deformity of lesser toes to be addressed with adequate surgical treatment using Weil surgery and plasty of the plantar plate until complete tear occurs;

G4 - severe injury to the MTPJ with anatomical injury to the plantar plate, complete dislocation in the joint, rigid hammertoe deformity of lesser toes, fibrous ankylosis of the interphalangeal joints to be addressed with adequate surgical treatment to correct claw deformity, Hohmann surgery and transarticular fixation of the MTPJ with a wire.

Therefore, sonographic scanning introduced in the algorithm of diagnosis of the extent of the plantar plate tear allows an objective approach to the choice of treatment strategy in complicated static multiplanar deformity of the forefoot accompanied by non-rigid hammertoe deformity of lesser toes.

\section{CONCLUSIONS}

1. Preoperative ultrasound imaging of the plantar surface of the foot for detecting the severity of plantar plate injury should be included in the diagnostic algorithm for patients with complicated multiplanar forefoot deformities accompanied by a non-rigid hammertoe deformity of lesser toes.

2. Preoperative ultrasound imaging of the plantar surface of the heads of the second and third metatarsal bones allows reduction in diagnostic errors assessing the extent of the plantar plate tear by $22.8 \%$.

3. An objective sonographic examination of the plantar plate tear facilitates an objective choice of surgical strategy to avoid an excessive volume of surgical intervention and optimize the timing for the procedure.

\section{REFERENCES}

1. Wang B., Guss A, Chalayon O, Bachus K,N, Barg A, Saltzman C,L. Deep transverse metatarsal ligament and static stability of lesser metatarsophalangeal joints: a cadaveric study. Foot Ankle Int., 2015, vol. 36, no. 5, pp. 573-578. DOI: 10.1177/1071100714563310

2. Savintsev A.M. Rekonstruktivno-plasticheskaia khirurgiia poperechnogo ploskostopiia [Reconstructive plastic surgery of transverse flatfoot]. SPb., Foliant, 2006, 23 p. (in Russian)

3. Klein E.E., Weil L. Jr., Weil L.S. Sr., Coughlin M.J., Knight J. Clinical examination of plantar plate abnormality: a diagnostic perspective. Foot Ankle Int., 2013, vol. 34, no. 6, pp. 800-804. DOI: 10.1177/1071100712471825

4. Tonogai I., Hayashi F., Tsuruo Y., Sairyo K. Distances from the deep plantar arch to the lesser metatarsals at risk during osteotomy: a fresh cadaveric study. J. Foot Ankle Res., 2018, vol. 11, pp. 57. DOI: 10.1186/s13047-018-0300-3

5. Roddy E., Zhang W., Doherty M. Prevalence and associations of hallux valgus in a primary care population. Arthritis Rheum., 2008, vol. 59, no. 6, pp. 857-862. DOI: 10.1002/art.23709

6. Baca E., E. Karaali, A. Duramaz, E. Ercin. Hallux valgus patients, why are they happy? Foot Ankle Orthop., 2017, vol. 2, no. 3. DOI: 10.1177/2473011417S000101

7. Barg A., Courville X.F., Nickisch F., Bachus K.N., Saltzman C.L. Role of collateral ligaments in metatarsophalangeal stability: a cadaver study. Foot Ankle Int., 2012, vol. 33, no. 10, pp. 877-882. DOI: 10.3113/FAI.2012.0877

8. Brogan K., Voller T., Gee C., Borbely T., Palmer S. Third-generation minimally invasive correction of hallux valgus: technique and early outcomes Int. Orthop., 2014, vol. 38, no. 10, pp. 2115-2121. DOI: 10.1007/s00264-014-2500-1

9. Protsko V.G. Vybor optimalnogo metoda lecheniia valgusnoi deformatsii pervogo paltsa stopy. Diss. kand. med. nauk [Choosing the optimal method for treating hallux valgus of the first toe. Cand. med. sci. diss.]. Moscow, 2004, 54 p. (in Russian)

10. Van Doninck D., Verschueren T., Matricali G.A., Van Opstal N., Scheys L., Vandeputte G. Screwless scarf osteotomy for hallux valgus: Evaluation of radiologic correction. Foot Ankle Surg., 2017, vol. 23, no. 4, pp. 255-260. DOI: 10.1016/j.fas.2016.07.002

11. Bock P., Kluger R., Kristen K.H., Mittlböck M., Schuh R., Trnka H.J. The scarf osteotomy with minimally invasive lateral release for treatment of hallux valgus deformity: intermediate and long-term results. J. Bone Joint Surg. Am., 2015, vol. 97, no. 15, pp. 1238-1245. DOI: 10.2106/JBJS.N.00971

12. Phisitkul P. Managing complications of lesser toe and metatarsophalangeal joint surgery. Foot Ankle Clin., 2018, vol. 23 , no. 1, pp. 145-156. DOI: $10.1016 /$ j.fcl.2017.09.010

13. Pentikainen I., Ojala R., Ohtonen P., Piippo J., Leppilahti J. Preoperative radiological factors correlated to long-term recurrence of hallux valgus following distal chevron osteotomy. Foot Ankle Int., 2014, vol. 35, no. 12, pp. 1262-1267. DOI: 10.1177/1071100714548703

14. Jeuken R.M., Schotanus M.G., Kort N.P., Deenik A., Jong B., Hendrickx R.P. Long-term follow-up of a randomized controlled trial comparing scarf to chevron osteotomy in hallux valgus correction. Foot Ankle Int., 2016, vol. 37, no. 7, pp. 687-695. DOI: 10.1177/1071100716639574

15. Thompson F.M., Hamilton W.G. Problems of the second metatarsophalangeal joint. Orthopedics, 1987, vol. 10, no. 1, pp. 83-89.

16. Lam K., Kong S., Chow Y. Percutaneous chevron osteotomy in treating hallux valgus: Hong Kong experience and mid-term results. J. Orthop. Trauma Rehabil., 2015, vol. 19, no. 1, pp. 25-30. DOI: 10.1016/j.jotr.2014.02.001

17. Lee M., Walsh J., Smith M.M., Ling J., Wines A., Lam P. Hallux valgus correction comparing Percutaneous Chevron/Akin (PECA) and Open Scarf/ Akin osteotomies. Foot Ankle Int., 2017, vol. 38, no. 8, pp. 838-846. DOI: 10.1177/1071100717704941

18. Yu G., Yu Y., Zhang P., Yang Y., Li B., Zhang M. [Surgical repair of chronic tears of the second plantar plate]. Zhongguo Xiu Fu Chong Jian Wai Ke Za Zhi, 2013, vol. 27, no. 12, pp. 1446-1449. (in Chinese)

19. Watson T.S., Reid D.Y., Frerichs T.L. Dorsal approach for plantar plate repair with Weil osteotomy: operative technique. Foot Ankle Int., 2014, vol. 35 , no. 7 , pp. $730-739$. DOI: $10.1177 / 1071100714536540$

20. Johansen J.K., Jordan M., Thomas M. Clinical and radiological outcomes after Weil osteotomy compared to distal metatarsal metaphyseal osteotomy in the treatment of metatarsalgia - a prospective study. Foot Ankle Surg., 2019, vol. 25, no. 4, pp. 488-494. DOI: 10.1016/j.fas.2018.03.002

21. Rivero-Santana A., Perestelo-Pérez L., Garcés G., Álvarez-Pérez Y., Escobar A., Serrano-Aguilar P. Clinical effectiveness and safety of Weil's osteotomy and distal metatarsal mini-invasive osteotomy (DMMO) in the treatment of metatarsalgia: A systematic review. Foot Ankle Surg., 2019, vol. 25 , no. 5 , pp. 565-570. DOI: 10.1016/j.fas.2018.06.004

22. Jastifer J.R., Coughlin M.J. Exposure via sequential release of the metatarsophalangeal joint for plantar plate repair through a dorsal approach without an intraarticular osteotomy. Foot Ankle Int., 2015, vol. 36, no. 3, pp. 335-338. DOI: 10.1177/1071100714553791

23. Huerta J.P., Lorente C.A., Carmona G.F.J. The Weil osteotomy: A comprehensive review. Rev. Esp. Podol., 2017, vol. 28, no. 2. DOI: 10.1016/j. repod.2017.10.003.

24. Yeo N.E., Loh B., Chen J.Y., Yew A.K., Ng S.Y. Comparison of early outcome of Weil osteotomy and distal metatarsal mini-invasive osteotomy for lesser toe metatarsalgia. J. Orthop. Surg. (Hong Kong), 2016, vol. 24, no. 3, pp. 350-353. DOI: 10.1177/1602400315 
25. Kramer W.C., Parman M., Marks R.M. Hammertoe correction with k-wire fixation. Foot Ankle Int., 2015 , vol. 36, no. 5, pp. 494-502. DOI: $10.1177 / 1071100714568013$

26. UK National Diagnostic Reference Levels (NDRLs), 2017. Public Health England. Available at: https://www.gov.uk/government/publications/ diagnostic-radiology-national-diagnostic-reference-levels-ndrls/ national-diagnostic-reference-levels-ndrls (accessed June 29, 2018).

27. Cherevtsov V.N., Protsko V.G., Zagorodnii N.V., Ketov M.S., Gorokhov A.V. Sposob opredeleniia tipa degenerativnogo razryva plantarnoi plastinki pliusnefalangovogo sustava vsledstvie peregruzochnoi metatarzalgii [The way of determining the type pf degenerative rupture of the metatarsophalangeal joint plantar plate due to overload metatarsalgia]. Patent RF no. 2699383, A 61 B 8/08, 2019. (in Russian)

28. Glants S. Mediko-biologicheskaia Statistika [Medical-and-biological statistics]. Ed. by N.E. Buzikashvili, D.V. Samoilov. M., Praktika, 1999, pp. 27-45. (in Russian)

29. Milczarek M.A., Milczarek J.J., Tomasik B., Łaganowski P., Nowak K., Domżalski M. Being overweight has limited effect on SCARF osteotomy outcome for hallux valgus correction. Int. Orthop., 2017, vol. 41, no. 4, pp. 765-772. DOI: 10.1007/s00264-017-3419-0

30. Besse J.L. Metatarsalgia. Orthop. Traumatol. Surg. Res., 2017, vol. 103, no. 1S, pp. S29-S39. DOI: 10.1016/j.otsr.2016.06.020

31. Doty J.F., Coughlin M.J. Metatarsophalangeal joint instability of the lesser toes and plantar plate deficiency. J. Am. Acad. Orthop. Surg., 2014, vol. 22, no. 4, pp. 235-245. DOI: 10.5435/JAAOS-22-04-235

32. Fleischer A.E., Hshieh S., Crews R.T., Waverly B.J., Jones J.M., Klein E.E., Weil L. Jr., Weil L.S. Sr. Association between second metatarsal length and forefoot loading under the second metatarsophalangeal joint. Foot Ankle Int., 2018, vol. 39, no. 5, pp. 560-567. DOI: 10.1177/1071100717753829

33. Prissel M.A., Hyer C.F., Donovan J.K., Quisno A.L. Plantar plate repair using a direct plantar approach: an outcomes analysis. J. Foot Ankle Surg., 2017, vol. 56, no. 3, pp. 434-439. DOI: 10.1053/j.jfas.2016.12.002

Received: 03.11.2020

\section{Information about the authors:}

1 Vitaliy N. Cherevtsov, M.D.,

City Clinical Hospital № 3 MH KK Krasnodar, Russian Federation,

Email: issled@list.ru

2 Alexander N. Blazhenko, M.D., Ph.D., Professor,

KubGMU, Krasnodar, Russian Federation

3 Sergey B. Bogdanov, M.D., Ph.D., Professor,

KubGMU, Krasnodar, Russian Federation

4 Alexey V. Mazalov, M.D.,

Moscow Research Centre Name after A.S. Loginov, Moscow, Russian Federation

5 Maksim S. Ketov, M.D.,

City Clinical Hospital № 1, Novokuznetsk, Russian Federation 